\title{
Consideration of corneal biomechanics in the diagnosis and management of keratoconus: is it important?
}

\author{
FangJun Bao ${ }^{1,2}$, Brendan Geraghty ${ }^{3}$, QinMei Wang ${ }^{1,2^{*}}$ and Ahmed Elsheikh $h^{3,4}$
}

\begin{abstract}
Keratoconus is a bilateral, non-inflammatory, degenerative corneal disease. The occurrence and development of keratoconus is associated with corneal thinning and conical protrusion, which causes irregular astigmatism. With the disruption of the collagen organization, the cornea loses its shape and function resulting in progressive visual degradation. Currently, corneal topography is the most important tool for the diagnosis of keratoconus, which may lead to false negatives among the patient population in the subclinical phase. However, it is now hypothesised that biomechanical destabilisation of the cornea may take place ahead of the topographic evidence of keratoconus, hence possibly assisting with disease diagnosis and management. This article provides a review of the definition, diagnosis, and management strategies for keratoconus based on corneal biomechanics.
\end{abstract}

Keywords: Keratoconus, In vivo, Corneal biomechanics, Corneal collagen cross-linking

\section{Background}

Keratoconus $(\mathrm{KC})$ is an idiopathic degenerative eye disease characterised by localized thinning and conical protrusion of the cornea, which typically develops in the inferior-temporal and central zones [1]. Consequently, visual acuity is reduced due to irregular astigmatism and high myopia resulting from asymmetric topographical changes in the anterior corneal surface. $\mathrm{KC}$ is the most prevalent form of corneal ectasia and affects all ethnicities [2-5], however, higher incidence has been reported in Asians when compared to Caucasians [6, 7]. While the aetiology and pathology of the disease is still not fully understood, various biochemical, cellular and microstructural differences have been reported in the literature. For instance, biochemical changes include increased activity of proteolytic enzymes and a decrease in their inhibitors $[8,9]$. Increased proteoglycan $(\mathrm{PG})$ content and altered distribution PG filaments have also been reported [10]. A progressive reduction in collagenproducing corneal keratocytes has been observed [11] as

\footnotetext{
*Correspondence: wangqm55@126.com

${ }^{1}$ The Affiliated Eye Hospital of Wenzhou Medical University, Wenzhou City 325027, China

${ }^{2}$ The Institution of Ocular Biomechanics, Wenzhou Medical University,

Wenzhou City 325027, China

Full list of author information is available at the end of the article
}

well as a disruption to the highly organized orthogonal arrangement of collagens [12] that is typically seen in healthy corneas $[13,14]$. Further, a decrease in the mean fibril diameter and interfibrillar spacing of individual collagens and undulation of collagen lamellae have been reported [10]. Since biomechanical stability is dependent on regulation and organization of structural components within the cornea, the aforementioned biochemical, cellular and microstructural alterations would be expected to have negative consequences on structural integrity and hence lead to corneal abnormal deformation under intraocular pressure. It is therefore no surprise that experimental studies of ex vivo $\mathrm{KC}$ corneas have reported abnormalities in biomechanical response to applied loads when compared to normal corneas $[15,16]$.

\section{Reviews}

\section{Keratoconus diagnosis techniques}

With the disruption of the collagen network, intraocular pressure-related stress causes a weakened cornea to bulge from its normal shape and become progressively conical. Consequently, corneal topography is the most widely used tool to detect $\mathrm{KC}$ [17]. Corneal shape parameters such as thin pachymetry, atypical pachymetry profile, irregular anterior curvature as well as increased 
posterior surface elevation, have all been used to detect $\mathrm{KC}$ at different stages of the disease [17]. While topography analysis is well-suited to characterising $\mathrm{KC}$ when clear geometrical changes have occurred in the cornea, its robustness reduces when attempting to assess mild, pathologic cases, especially in subclinical or early $\mathrm{KC}$ [17]. However, changes in corneal geometric features are secondary signs of $\mathrm{KC}$ whereas the earliest initiating changes would occur within the microstructures and then the biomechanical properties of cornea. Therefore, understanding the cornea's biomechanical behaviour is important for the detection of subclinical $\mathrm{KC}$, while changes in topography are still insufficient to provide conclusive evidence of $\mathrm{KC}$ progression [18]. However, in vivo measurement of corneal biomechanics remains a difficult task at this stage and only two commercially available instruments have been proposed to assist in the diagnosis of KC. These two instruments are summarized below.

\section{Ocular response analyzer}

The ocular response analyzer (ORA) became commercially available in 2005 and was the first device capable of evaluating the biomechanical response of the cornea in vivo (Fig. 1). The device provides two biomechanical metrics: corneal hysteresis $(\mathrm{CH})$ and corneal resistance factor (CRF), both of which are influenced by the viscoelastic behaviour of corneal tissue [19]. Clinically measured metrics provided by the ORA have been widely used to assess the biomechanical response of the cornea. Compared with normal patients, both $\mathrm{CH}$ and CRF decrease in $\mathrm{KC}$ corneas indicating mechanical softening of

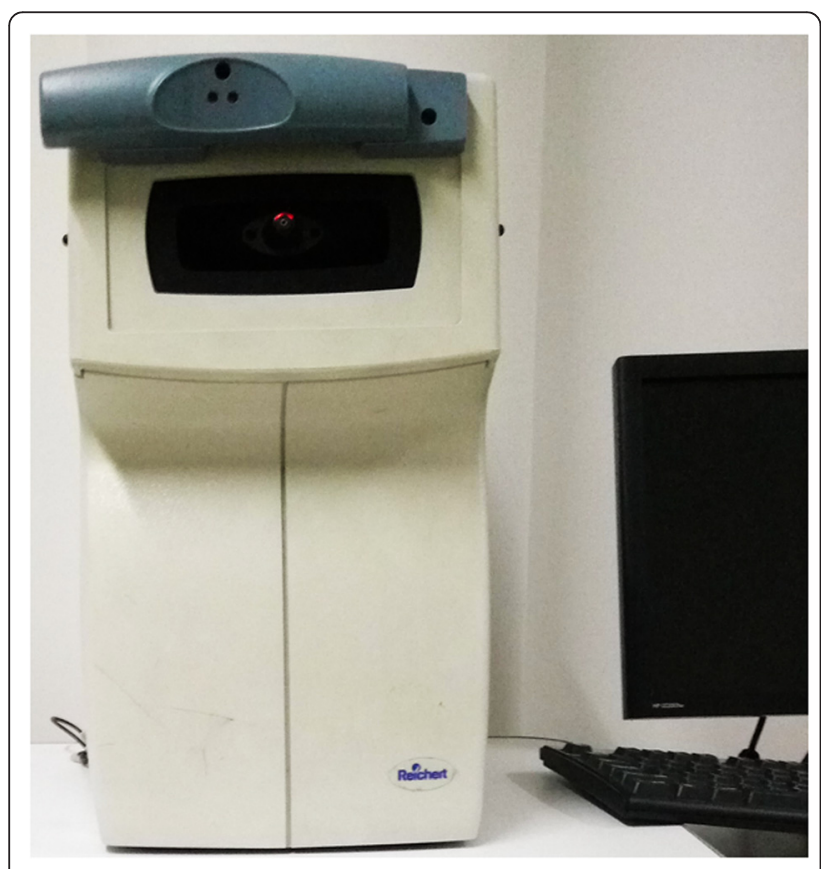

Fig. 1 Photo of the Ocular Response Analyzer (ORA) the stroma [20]. However, when comparing these biomechanical metrics, it is clear that a wide substantial overlap exists between normal corneas and keratoconic corneas [21,22] and so they have not been as effective in identifying $\mathrm{KC}$ as first anticipated. Furthermore, the exact correlation between these metrics and the established mechanical properties of tissue (such as tangent modulus) is still unknown. Thus, the ORA needs to be complemented with other diagnostic imaging tools to obtain a reliable diagnosis of $\mathrm{KC}$. With the introduction of a new software update (version 2.0) in 2009, the ORA now computes 37 new parameters that describe the waveform of the ORA applanation signal. These parameters show promise in providing additional biomechanical information about the KC cornea [23, 24]. However, specific explanation of the meaning of these parameters has not been provided by the manufacturers, and they still require thorough clinical validation before they can be used clinically.

\section{Corvis ST}

The Corvis ST (CVS) is another non-contact device that was introduced in 2010 and provides information about the biomechanical response of the cornea using dynamic Scheimpflug imaging analysis (Fig. 2). The CVS captures approximately 140 cross-sectional images of the cornea during the air-puff induced dynamic deformation [25] using its high-speed camera system. The corneas' response to air pressure is characterized by ten deformation parameters, some of which are strongly correlated with the tissue's mechanical stiffness. As shown in a previous study, the maximum deformation amplitude of keratoconic corneas is much greater than that of normal corneas [26]. However, the usefulness of CVS to evaluate $\mathrm{KC}$ severity and diagnose

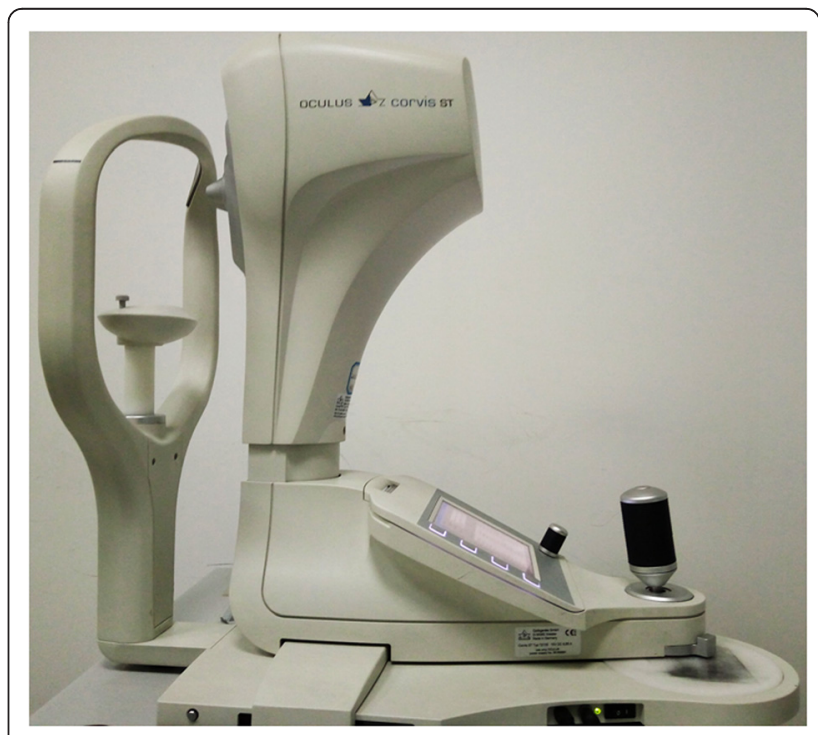

Fig. 2 Photo of the Corvis ST (CVS) 
subclinical $\mathrm{KC}$ is yet to be determined. In addition to the ten metrics provided by the device, the inclusion of a highspeed Scheimpflug camera allows for precise monitoring of cornea cross-sectional deformation under the applied air pressure. The capability to monitor in vivo response of the cornea provides biomedical engineers with essential information that can be used to determine more precise biomechanical properties of the tissue. Work is now progressing to utilise this device to produce regional estimations of in vivo corneal stiffness, which may allow for better planning of the treatment and management of $\mathrm{KC}$.

\section{Other devices}

In addition to the ORA and CVS, several other technologies have been developed to evaluate corneal biomechanical parameters in vivo such as optical coherence tomography [27], supersonic shear wave imaging (SSI) [28], confocal microscopy [29], applanation resonance tonometry (ART) [30], acoustic radiation force (ARF) [31] and scanning acoustic microscopy [32]. However, validation of these technologies in human eyes will be essential before using them to improve the accuracy of $\mathrm{KC}$ diagnosis.

The current lack of reliable devices that are capable of characterising true corneal material properties in vivo has meant that the biomechanics of $\mathrm{KC}$ have only been investigated to a limited extent. It is now becoming evident that a global biomechanical assessment of the cornea may not be sufficient to fully characterize this typically asymmetric disease. Spatial location of focal weakening in the cornea will be necessary to detect the disease at its early stages as well as fully characterise its progression.

\section{Keratoconus management techniques}

$\mathrm{KC}$ is currently managed using a number of methods ranging from contact lenses to intra-stromal corneal ring segment (ICRS) implants and collagen crosslinking $(\mathrm{CXL})$, penetrating keratoplasty $(\mathrm{PK})$ and deep anterior lamellar keratoplasty (DALK). However, the method of management used is dependent on the severity of the ectasia. In early stages, spectacles can correct refractive errors sufficiently. As the disease progresses [2], this method becomes unsuitable for correcting the irregular astigmatism associated with $\mathrm{KC}$. In mild to moderate $\mathrm{KC}$, contact lenses have become the most common and successful method of management providing improved visual acuity whilst decreasing the need for surgical interventions [33]. Although soft lenses provide increased comfort for the wearer, rigid lenses are more prevalent since high levels of irregular astigmatism cannot be corrected with other lens types [34, 35]. Recently, CXL treatment of the cornea is becoming the standard method for halting the progression of the disease at early stages and prevent further deterioration, which may make tissue replacement necessary. PK and more recently, DALK, are used to replace either the entire cornea or $95 \%$ of the stromal layers of the cornea, respectively, with healthy donor tissue in advanced cases of $\mathrm{KC}$ that cannot be successfully managed with other methods.

\section{Contact lenses}

Contact lenses aim to improve the anterior curvature of the cornea and increase visual acuity. The lens is held in place by forces generated between the tear film, lens and eye, and several options are currently available for use on keratoconic corneas. Bespoke soft lens options, such as the KeroSoft ${ }^{\circ}$ lens, are individually lathe cut to fit the specific irregularity of a patients' cornea resulting in a close fit between the lens and eye. Rigid lenses are made from oxygen permeable material but the degree of fit between the lens and eye varies. Originally, it was hoped that the lens bearing pressure on the cornea could correct or stabilise the ectasia by flattening the cone (flat fit) [36], but this can result in abrasion and scarring of the cornea [37] as well as progression of the cone. In mild $\mathrm{KC}$, an ideal fit can be achieved and the lens is usually intended to rest on the apex of the cone and peripheral cornea (three-point touch). However, as the cone progresses, a compromised fit may need to be accepted as long as it does not cause damage to the cornea [38].

\section{Intra-stromal corneal ring segments}

In contrast to the spectacles and contact lens short-term solutions, which aim to improve visual acuity by improving the anterior curvature of the cornea, more long-term invasive clinical interventions are available. ICRS implants aim to improve the shape of the cornea and halt the progression of the cone. ICRS implants are inserted into the stroma by creating an incision in the peripheral region of the cornea and decrease asymmetrical astigmatism and convexity of the cone [39, 40]. Although there have been no statistically significant differences observed in $\mathrm{CH}$ and $\mathrm{CRF}$ parameters obtained from the ORA following use of the ICRS [41], the introduction of rigid components to the stroma would be expected to affect the biomechanical behaviour of the tissue. This could be due to tissue scarring within the stroma resulting from the introduction of the ICRS implants or changes in the overall mechanical response of the tissue, particularly in the peripheral region where the implant has been introduced.

\section{Corneal collagen cross-linking}

CXL is commonly achieved by removing the epithelium and saturation of the stroma with riboflavin followed by irradiation of the central region of the cornea using ultraviolet-A light at $365-370 \mathrm{~nm}$ [42]. The procedure 
induces crosslinks between the collagen fibrils and within the proteoglycan-rich coating surrounding them [43] as well as limited linkages among collagen molecules and among proteoglycan core proteins [44]. The outcome of this procedure is an overall increase in mechanical strength [45], which usually halts the progression of the cone [46]. CXL is now fast becoming the most commonly used technique as it can be used to halt the progression of the cone especially at an early stage [47] and with minimum stromal thickness of at least $400 \mu \mathrm{m}$, thereby reducing further degradation of visual acuity and limiting the need for corneal transplants.

\section{Keratoplasty}

Advanced cases of $\mathrm{KC}$ with high corneal curvature, high astigmatism, low visual acuity, presence of corneal scarring and/or poor contact lens tolerance may require PK [48-50], in which the entire thickness of the cornea is removed and replaced by healthy corneal tissue $[2,48]$. However, normal stromal architecture cannot be fully recovered in full-thickness graft wounds [51-53]. On the other hand, if Descemet's membrane and the endothelium are to remain intact $[54,55]$, DALK should be a reasonable alternative [56], in which only the stromal layers of the cornea are removed and replaced thereby reducing the risk of endothelial rejection and transplant failure. Nevertheless, long-term abnormalities in collagen fibril orientation and spatial organisation around the entire graft margin have been observed following PK, which may affect corneal biomechanical behaviour and graft stability in the long term [57].

\section{Biomechanical changes in $\mathrm{KC}$ with different management techniques}

Although all current $\mathrm{KC}$ management techniques involve mechanical interaction with or mechanical changes to the cornea, the design and planning of these interventions do not consider the mechanical properties of the cornea either pre- or post-intervention. For instance, possible hypoxic effects can occur from prolonged lens wear resulting in oedema [58], and hence increased thickness with soft contact lenses even though the materials used have high oxygen permeability. In rigid lens wear, where the interaction between the lens and cornea can be even more pronounced, changes in corneal shape with possible biochemical, cellular and microstructural responses may have subsequent consequences for the overall biomechanical integrity of the cornea. Postoperative ORA assessments have shown that DALK treated corneas return to biomechanical metrics similar to those of normal corneas whereas the corresponding values for PK treated corneas are significantly lower, indicating weaker biomechanical properties $[59,60]$. However, the most significant changes observed are those obtained using CXL. Experimental crosslinking studies have reported human corneal stiffness increases in the region of $300 \%$ using riboflavin/UVA treatment [45], but surprisingly no change in inter-laminar cohesion [61]. These changes in corneal stiffness could not be properly validated so far in vivo due to limitations with current clinical biomechanical assessment techniques as discussed in this paper.

\section{Conclusion}

The current inability to measure in vivo corneal biomechanical properties has been a major obstacle in planning and assessing the outcomes of $\mathrm{KC}$ interventions. While diagnosis techniques rely on abnormal cornea tomography parameters, changes in corneal geometry are secondary signs of the disease. Consequently, the efficacy of using these parameters is reduced when attempting to assess mild and subclinical cases. Since the earliest changes to KC corneas occur within the microstructure, in vivo assessment of corneal biomechanics may be a more appropriate approach to detecting subclinical KC. The ORA and CVS provide the first step towards the assessment of in vivo of biomechanical properties. In particular, the inclusion of a high-speed Scheimpflug camera on the CVS allows detailed monitoring of the corneas response to an applied air pressure. This invaluable information may be used by biomedical engineers to determine more detailed corneal biomechanical properties and develop a method of identifying the spatial location of focal weakening within the tissue, and hence enable early detection of subclinical $\mathrm{KC}$ and optimisation of management techniques to individual patient's needs.

\section{Authors' contributions \\ $F J B, G B, Q M W$, and EA contributed to the design of the manuscript. FJB and GB reviewed papers and drafted the manuscript; QMW and EA critically revised the manuscript for important intellectual content. All authors read and approved the final manuscript.}

\section{Competing interests \\ The authors declare that they have no competing interests.}

\section{Author details}

${ }^{1}$ The Affiliated Eye Hospital of Wenzhou Medical University, Wenzhou City 325027, China. ${ }^{2} T h e$ Institution of Ocular Biomechanics, Wenzhou Medical University, Wenzhou City 325027, China. ${ }^{3}$ School of Engineering, University of Liverpool, Liverpool City L69 3GH, UK. ${ }^{4}$ NIHR Biomedical Research Centre for Ophthalmology, Moorfields Eye Hospital NHS Foundation Trust and UCL Institute of Ophthalmology, London City, UK.

Received: 17 September 2015 Accepted: 13 June 2016

Published online: 04 July 2016

\footnotetext{
References

1. Auffarth GU, Wang L, Völcker HE. Keratoconus evaluation using the Orbscan Topography System. J Cataract Refract Surg. 2000;26(2):222-8 Rabinowitz YS. Keratoconus. Surv Ophthalmol. 1998:42(4):297-319.

3. Wagner H, Barr JT, Zadnik K. Collaborative Longitudinal Evaluation of Keratoconus (CLEK) Study: methods and findings to date. Cont Lens Anterior Eye. 2007;30(4):223-32.
} 
4. Weed KH, MacEwen CJ, Giles T, Low J, McGhee CN. The Dundee university Scottish keratoconus study: demographics, corneal signs, associated diseases, and eye rubbing. Eye (Lond). 2008;22(4):534-41.

5. Owens H, Gamble GD, Bjornholdt MC, Boyce NK, Keung L. Topographic indications of emerging keratoconus in teenage New Zealanders. Cornea. 2007;26(3):312-8.

6. Pearson AR, Soneji B, Sarvananthan N, Sandford-Smith JH. Does ethnic origin influence the incidence or severity of keratoconus? Eye (Lond). 2000;14(Pt4):625-8.

7. Georgiou T, Funnell CL, Cassels-Brown A, O'Conor R. Influence of ethnic origin on the incidence of keratoconus and associated atopic disease in Asians and white patients. Eye (Lond). 2004;18(4):379-83.

8. Cristina Kenney M, Brown DJ. The cascade hypothesis of keratoconus. Cont Lens Anterior Eye. 2003;26(3):139-46.

9. Kenney MC, Chwa M, Atilano SR, Tran A, Carballo M, Saghizadeh M, et al. Increased levels of catalase and cathepsin V/L2 but decreased TIMP-1 in keratoconus corneas: evidence that oxidative stress plays a role in this disorder. Invest Ophthalmol Vis Sci. 2005;46(3):823-32.

10. Akhtar S, Bron AJ, Salvi SM, Hawksworth NR, Tuft SJ, Meek KM Ultrastructural analysis of collagen fibrils and proteoglycans in keratoconus. Acta Ophthalmol. 2008;86(7):764-72.

11. Ku JY, Niederer RL, Patel DV, Sherwin T, McGhee CN. Laser scanning in vivo confocal analysis of keratocyte density in keratoconus. Ophthalmology. 2008;115(5):845-50.

12. Meek K, Tuft S, Huang Y, Gill PS, Hayes S, Newton RH, et al. Changes in collagen orientation and distribution in keratoconus corneas. Invest Ophthalmol Vis Sci. 2005;46(6):1948-56.

13. Meek KM, Blamires T, Elliott GF, Gyi TJ, Nave C. The organisation of collagen fibrils in the human corneal stroma: a synchrotron X-ray diffraction study. Curr Eye Res. 1987;6(7):841-6.

14. Smolek MK, Beekhuis WH. Collagen fibril orientation in the human corneal stroma and its implications in keratoconus. Invest Ophthalmol Vis Sci. 1997;38(7):1289-90.

15. Nash IS, Greene PR, Foster CS. Comparison of mechanical properties of keratoconus and normal corneas. Exp Eye Res. 1982;35(5):413-24.

16. Andreassen $\Pi$, Simonsen $\mathrm{AH}$, Oxlund $\mathrm{H}$. Biomechanical properties of keratoconus and normal corneas. Exp Eye Res. 1980;31(4):435-41.

17. Piñero DP, Nieto JC, Lopez-Miguel A. Characterization of corneal structure in keratoconus. J Cataract Refract Surg. 2012;38(12):2167-83.

18. Piñero DP, Alio JL, Barraquer RI, Michael R, Jiménez R. Corneal biomechanics, refraction, and corneal aberrometry in keratoconus: an integrated study. Invest Ophthalmol Vis Sci. 2010;51(4):1948-55.

19. Roberts CJ. Concepts and misconceptions in corneal biomechanics. J Cataract Refract Surg. 2014;40(6):862-9.

20. Seiler T, Huhle S, Spoerl E, Kunath H. Manifest diabetes and keratoconus: a retrospective case-control study. Graefes Arch Clin Exp Ophthalmol. 2000;238(10):822-5.

21. Fontes BM, Ambrósio R Jr, Velarde GC, Nosé W. Ocular response analyzer measurements in keratoconus with normal central corneal thickness compared with matched normal control eyes. J Refract Surg. 2011;27(3):209-15.

22. Johnson RD, Nguyen MT, Lee N, Hamilton DR. Corneal biomechanical properties in normal, forme fruste keratoconus, and manifest keratoconus after statistical correction for potentially confounding factors. Cornea. 2011;30(5):516-23.

23. Mikielewicz M, Kotliar K, Barraquer Rl, Michael R. Air-pulse corneal applanation signal curve parameters for the characterisation of keratoconus. Br J Ophthalmol. 2011;95(6):793-8.

24. Wolffsohn JS, Safeen S, Shah S, Laiquzzaman M. Changes of corneal biomechanics with keratoconus. Cornea. 2012;31(8):849-54.

25. Valbon BF, Ambrósio R Jr, Fontes BM, Luz A, Roberts CJ, Alves MR. Ocular biomechanical metrics by CorVis ST in healthy Brazilian patients. J Refract Surg. 2014;30(7):468-73.

26. Ali NQ, Patel DV, McGhee CN. Biomechanical responses of healthy and keratoconic corneas measured using a non contact Scheimpflug tonometer. Invest Ophthalmol Vis Sci. 2014;55(6):3651-9.

27. Ford MR, Dupps Jr WJ, Rollins AM, Roy AS, Hu Z. Method for optical coherence elastography of the cornea. J Biomed Opt. 2011;16(1):016005.

28. Touboul D, Gennisson JL, Nguyen TM, Robinet A, Roberts CJ, Tanter M, et al. Supersonic shear wave elastography for the in vivo evaluation of transepithelial corneal collagen cross-linking. Invest Ophthalmol Vis Sci. 2014;55(3):1976-84.

29. Scarcelli G, Besner S, Pineda R, Kalout P, Yun SH. In vivo biomechanical mapping of normal and keratoconus corneas. JAMA Ophthalmol. 2015;133(4):480-2.
30. Beckman Rehnman J, Behndig A, Hallberg P, Lindén C. Increased corneal hysteresis after corneal collagen crosslinking: a study based on applanation resonance technology. JAMA Ophthalmol. 2014;132(12):1426-32.

31. Urs R, Lloyd HO, Silverman RH. Acoustic radiation force for noninvasive evaluation of corneal biomechanical changes induced by cross-linking therapy. J Ultrasound Med. 2014;33(8):1417-26.

32. Beshtawi IM, Akhtar R, Hillarby MC, O'Donnell C, Zhao X, Brahma A, et al. Biomechanical Changes of Collagen Cross-Linking on Human Keratoconic Corneas Using Scanning Acoustic Microscopy. Curr Eye Res. 2016;41(5):609-15.

33. Bilgin LK, Yilmaz S, Araz B, Yüksel SB, Sezen T. 30 years of contact lens prescribing for keratoconic patients in Turkey. Cont Lens Anterior Eye. 2009;32(1):16-21.

34. Zadnik K, Barr JT, Edrington TB, Everett DF, Jameson M, McMahon TT, et al. Baseline findings in the collaborative longitudinal evaluation of keratoconus (CLEK) study. Invest Ophthalmol Vis Sci. 1998;39(13):2537-46.

35. Lim N, Vogt U. Characteristics and functional outcomes of 130 patients with keratoconus attending a specialist contact lens clinic. Eye (Lond). 2002;16(1):54-9.

36. Hartstein J. Keratoconus that developed in patients wearing corneal contact lenses. Report of four cases. Arch Ophthalmol. 1968;80(3):345-6.

37. Korb DR, Finnemore VM, Herman JP. Apical changes and scarring in keratoconus as related to contact lens fitting techniques. J Am Optom Assoc. 1982:53(3):199-205.

38. McMonnies CW. Keratoconus fittings: apical clearance or apical support? Eye Contact Lens. 2004;30(3):147-55.

39. Akaishi L, Tzelikis PF, Raber IM. Ferrara intracorneal ring implantation and cataract surgery for the correction of pellucid marginal corneal degeneration. J Cataract Refract Surg. 2004;30(11):2427-30.

40. Zare MA, Hashemi H, Salari MR. Intracorneal ring segment implantation for the management of keratoconus: safety and efficacy. J Cataract Refract Surg. 2007;33(11):1886-91.

41. Dauwe C, Touboul D, Roberts CJ, Mahmoud AM, Kérautret J, Fournier P, et al. Biomechanical and morphological corneal response to placement of intrastromal corneal ring segments for keratoconus. J Cataract Refract Surg. 2009;35(10):1761-7.

42. Wollensak G, Spoerl E, Seiler T. Riboflavin/ultraviolet-a-induced collagen crosslinking for the treatment of keratoconus. Am J Ophthalmol. 2003;135(5):620-7.

43. Hayes S, Kamma-Lorger CS, Boote C, Young RD, Quantock AJ, Rost A, et al. The effect of riboflavin/UVA collagen cross-linking therapy on the structure and hydrodynamic behaviour of the ungulate and rabbit corneal stroma. PLoS One. 2013;8(1):e52860.

44. Zhang Y, Conrad AH, Conrad GW. Effects of ultraviolet-A and riboflavin on the interaction of collagen and proteoglycans during corneal cross-linking. J Biol Chem. 2011;286(15):13011-22.

45. Wollensak G. Crosslinking treatment of progressive keratoconus: new hope. Curr Opin Ophthalmol. 2006;17(4):356-60.

46. Caporossi A, Mazzotta C, Baiocchi S, Caporossi T. Long-term results of riboflavin ultraviolet a corneal collagen cross-linking for keratoconus in Italy: the Siena eye cross study. Am J Ophthalmol. 2010;149(4):585-93.

47. Gomes JA, Tan D, Rapuano CJ, Belin MW, Ambrósio R Jr, Guell JL, et al. Global consensus on keratoconus and ectatic diseases. Cornea. 2015;34(4):359-69.

48. Sray WA, Cohen EJ, Rapuano CJ, Laibson PR. Factors associated with the need for penetrating keratoplasty in keratoconus. Cornea. 2002;21(8):784-6.

49. Tuft SJ, Moodaley LC, Gregory WM, Davison CR, Buckley RJ. Prognostic factors for the progression of keratoconus. Ophthalmology. 1994;101(3):439-47.

50. Reeves SW, Stinnett S, Adelman RA, Afshari NA. Risk factors for progression to penetrating keratoplasty in patients with keratoconus. Am J Ophthalmol. 2005;140(4):607-11.

51. Hayes S, Young R, Boote C, Hawksworth N, Huang Y, Meek KM. A structural investigation of corneal graft failure in suspected recurrent keratoconus. Eye (Lond). 2010;24(4):728-34.

52. Farley MK, Pettit TH. Traumatic wound dehiscence after penetrating keratoplasty. Am J Ophthalmol. 1987;104(1):44-9.

53. Pettinelli DJ, Starr CE, Stark WJ. Late traumatic corneal wound dehiscence after penetrating keratoplasty. Arch Ophthalmol. 2005;123(6):853-6.

54. Watson SL, Ramsay A, Dart JK, Bunce C, Craig E. Comparison of deep lamellar keratoplasty and penetrating keratoplasty in patients with keratoconus. Ophthalmology. 2004;111(9):1676-82.

55. Funnell CL, Ball J, Noble BA. Comparative cohort study of the outcomes of deep lamellar keratoplasty and penetrating keratoplasty for keratoconus. Eye (Lond). 2006;20(5):527-32.

56. Sugita J, Kondo J. Deep lamellar keratoplasty with complete removal of pathological stroma for vision improvement. Br J Ophthalmol. 1997;81(3):184-8. 
57. Boote C, Dooley EP, Gardner SJ, Kamma-Lorger CS, Hayes S, Nielsen K, et al. Quantification of collagen ultrastructure after penetrating keratoplasty implications for corneal biomechanics. PLoS One. 2013;8(7):e68166.

58. Holden BA, Mertz GW. Critical oxygen levels to avoid corneal edema for daily and extended wear contact lenses. Invest Ophthalmol Vis Sci. 1984;25(10):1161-7.

59. Hosny M, Hassaballa MA, Shalaby A. Changes in corneal biomechanics following different keratoplasty techniques. Clin Ophthalmol. 2011;5:767-70.

60. Abdelkader A. Influence of different keratoplasty techniques on the biomechanical properties of the cornea. Acta Ophthalmol. 2013;91(7):e567-72.

61. Wollensak G, Sporl E, Mazzotta C, Kalinski T, Sel S. Interlamellar cohesion after corneal crosslinking using riboflavin and ultraviolet A light. Br J Ophthalmol. 2011;95(6):876-80

Submit your next manuscript to BioMed Central and we will help you at every step:

- We accept pre-submission inquiries

- Our selector tool helps you to find the most relevant journal

- We provide round the clock customer support

- Convenient online submission

- Thorough peer review

- Inclusion in PubMed and all major indexing services

- Maximum visibility for your research

Submit your manuscript at www.biomedcentral.com/submit
Biomed Central 